\title{
MONITORING OF THE TRACK GEOMETRY QUALITY AROUND THE PORTALS OF NEW TUNNEL CONSTRUCTION TURECKY VRCH - PRELIMINARY RESULTS
}

\begin{abstract}
At the beginning, the contribution deals with the characteristics of conventional structure (track skeleton placed in the ballast) and unconventional structure (slab track) of railway superstructure. The trial section is characterized in the next part where measurements of relative track geometry are made at regular intervals (spring and autumn) using continuous measuring device (manual measuring trolley $K R A B^{T M}$ - Light). There is made the analysis of measurements made between 2012 - 2013 at the end of the contribution; with a view to assessing the quality of track geometry during particular sections monitored with in-built conventional and unconventional structure of railway superstructure. It also includes transition areas between these structures and an analysis of possible causes of variations in track geometry of modernized railway sections monitored.
\end{abstract}

Keywords: Railway track, conventional railway superstructure, slab track, track geometry, diagnostics.

\section{Introduction}

Considering the railway operation, a standard structure of railway superstructure has been proven for many decades which is historically also known to be capable of ensuring a relatively long period of operational capacity of the railway line. From a structural point of view, such a railway track with the standard structure of railway superstructure is referred to as a railway track whose track skeleton is stored in railway ballast. In the case of high line tonnage and axle load, increasing track speeds which are associated with the high quality requirements for track geometry, it appears that such a structure has its operational (in terms of guaranteeing the long-term safety and reliability of the track) and economical (in terms of the cost of track maintenance) limits. Standard structure of railway superstructure is characterized by "floating" placement of track skeleton, which causes the growth of dynamic horizontal and vertical forces during each passage of a rail vehicle or a train. They may and usually cause gradual degradation of track geometry which subsequently leads to restless driving of rail vehicles. The elimination of irregularities in track geometry - the quality of the track - forces the operator in a period of time to remove irregularities of track diagnosed by time and costly maintenance works. This phenomenon grows with increasing track speed and thus increases the cost of maintaining and share of track possessions, which reduce the attractiveness of the track for a passenger. It is sufficient, however, if only the weakest structural element of the standard railway superstructure is replaced in railway track, and the track ballast is another, more appropriate structural element which shows no plastic behaviour. Such replacement is a structure in which the track skeleton is concreted (monolithic structure) or placed on a concrete or asphalt substructure (layered structure), thus the design of railway track which is referred to as unconventional superstructure. Currently, thus conceived railway track is referred to as a slab track in which the required flexibility of the railway superstructure system for the wheel/rail is ensured using the flexible structural elements, disposed between the rail and the sleeper and/or under the sleeper.

The term slab track, as defined in [1], refers to such a structure of railway superstructure in which a spread function of railway ballast is replaced by reinforced materials, and which is placed on a concrete or asphalt substructure (slab). The structure of slab track proved to be practical and preferred structural system of railway superstructure in many railway reports, which has led to its spread practically all over the world. The essential reason for building the structure of slab track is the fact that its construction gives high stability of the track which is associated with a smooth movement of vehicles and at the same time with driving comfort for the passenger and the operator with significantly lower maintenance requirements and thus the possessions and finance. This high driving comfort can be obtained, in the case of the application of standard structure of railway superstructure, only with the connection with very high operating costs.

In general, the structure of slab track currently applies mainly to high-speed lines and lines that have high line tonnage where the cost of maintaining the track with the standard structure

\footnotetext{
* Libor Izvolt, Janka Sestakova, Michal Smalo, Zuzana Gocalova

Department of Railway Engineering and Track Management, Faculty of Civil Engineering, University of Zilina, Slovakia,

E-mail: libor.izvolt@fstav.uniza.sk
} 
of railway superstructure grows strongly. At the same time, however, this structure also promotes in the upgraded sections of the standard tracks (track speed up to $160 \mathrm{~km} \cdot \mathrm{h}^{-1}$ ), or tracks for higher speeds (track speed of $160 \mathrm{~km} \cdot \mathrm{h}^{-1}<\mathrm{V} \leq 200 \mathrm{~km} \cdot \mathrm{h}^{-1}$ ) and, in particular, to the tunnel clearance gauge, as there are required properties of the subgrade which do not show settlement of foundation. Furthermore, the use of the slab track structure has a positive impact on the size of the investment costs of tunnel realization, due to the smaller tunnel clearance gauge, in the case of new tunnels, or excluding economically demanding reconstruction of tunnel, in the case of its electrification on the existing tracks. The structures of slab track and bridges offer the application of subgrade without the settlement of foundation, and therefore, the application of this structure is also possible in these track sections.

In connection with the modernization of the trans-European corridor V. Venezia - Trieste / Koper - Ljubljana - Budapest Chop - Lvov; with a branch Va, passing through the territory of the Slovak Republic in the section of Bratislava - Zilina Kosice - Cierna nad Tisou - Chop was, under the construction of Railways of the Slovak Republic (ZSR). Modernization of railway track Nove Mesto nad Vahom - Puchov, in track section Nove Mesto nad Vahom - Trencianske Bohuslavice, designed by the construction contractor (REMING Consult, a. s.) and the purchaser (DG Slovak Railways - DG SR) and approved the structure of slab track type RHEDA $2000^{\circledR}$. After analyzing alternative solutions of routings around Turecky vrch in the current track of railway line and a new route - tunnel variant - the purchaser decided for the tunnel variant. It is considered that the change of routing of a railway line through the tunnel will increase the current track speed while minimizing adverse impacts on the protected landscape area where the track is led through. Another advantage of the tunnel variant in the decision making process of routing was that the construction of a tunnel did not restrict railway traffic because the tunnel was pierced outside the axes of original track.

In the view of the fact that in the case of necessary maintenance, or future repair and reconstruction works, the implementation of these works in the tunnel is complex. Moreover, due to the reduction of the amount of rock mined from the tunnel profile, which did not have further use, the structure of slab track, which has a lower structural thickness as in the case of using a standard structure of railway superstructure, was the appropriate solution.

\section{Characteristics of the test section with the unconventional structure of railway superstructure}

Modernization of above track section started in September 2009 and ended in May 2013, while the operation started in October 2012. The railway tunnel Turecky vrch, which is part of the track section, is the first tunnel in Slovakia designed and implemented according to the technical specifications for interoperability for conventional lines. It is convenient to the latest trends in tunnel and railway construction and should become a model for all future tunnels which will be built in Slovakia in terms of the modernization of railway lines. Doubletrack railway tunnel Turecky vrch is designed to structure gauge UIC C with the track-centre distance $4200 \mathrm{~mm}$. The total length of the tunnel is $1775 \mathrm{~m}$, while the tunnel tube of the section excavated has the length of $1738.5 \mathrm{~m}$ and thereon pierced sections of the south portal length of $25 \mathrm{~m}$ and northern portal length of $10 \mathrm{~m}$. There is a single cross-section of double-track tunnel with a radius of tunnel tube of $6.1 \mathrm{~m}$ throughout the entire length of the tunnel, including portal sections; there are only two chambers in the middle of the tunnel for tensioning mechanism spring for the overhead lines with advanced cross-section. Doubletrack in the tunnel is designed for the speed of $200 \mathrm{~km} . \mathrm{h}^{-1}$ with the reverse curves of the radii $2000 \mathrm{~m}$.

The structure of the slab track was designed, as already mentioned, due to the reduction in the slope area and also due to the durability and fixation of the track geometry and its minimum maintenance in the operation. The structure of the ST of the RHEDA $2000^{\circledR}$ system applied passes through the different types of subgrade. It starts before the south portal and passes through entire tunnel. Then, the structure of the slab track continues on the bridges and earthworks behind the north portal. The structure of the slab track itself also includes transition areas on both ends which ensure a smooth transition (smooth change of stiffness) from the rigid structure of the slab track o the flexible standard structure of railway superstructure. The total length of the slab track structure is $2280.145 \mathrm{~m}$ (it begins in new $\mathrm{km} 102.459825$ and ends in new $\mathrm{km} 104.740$ 000), while its particular parts: transition area $-45.175 \mathrm{~m}$, tunnel $1775.000 \mathrm{~m}$, bridges $-34.770 \mathrm{~m}$ and earthwork $-425.200 \mathrm{~m}$.

It is clear from the previous text that the structure of the slab track of RHEDA $2000^{\circledR}$ system applied is not structurally the same on the modernized track section due to differences in the stiffness of the subgrade (tunnel bottom, bridge and railway substructure of earthwork), but is modified, which is reflected in the thickness of the concrete structure and also its reinforcements. The structure of the slab track is divided into 3 basic structural types in the track section in question as follows [2] and [3]:

1. In the tunnel - Figs. 1 and 2: monolithic reinforced concrete slab of variable thickness (according to track superelevation) - concrete class C 35/45 with two-block sleepers B355.3 W60M concreted, lying on the concrete bottom of the tunnel tube.

2. On the earthworks - Figs. 3 and 4: monolithic reinforced concrete slab of constant thickness $240 \mathrm{~mm}$ - concrete class C 35/45 with two-block sleepers B355.3 W60M concreted (marked as TCL), lying on a monolithic slab of plain concrete class C 12/15 of constant thickness of $300 \mathrm{~mm}$ (marked as 
HBL). Track superelevation in curves is made up of sloping plain of sub-ballast surface.

3. On the bridges - Figs. 5 and 6: monolithic reinforced concrete slab of variable thickness (according to track superelevation)
- concrete class C 35/45 with two-block sleepers concreted, lying on the separating layer Styrodur + foil on the structure of the bridge.

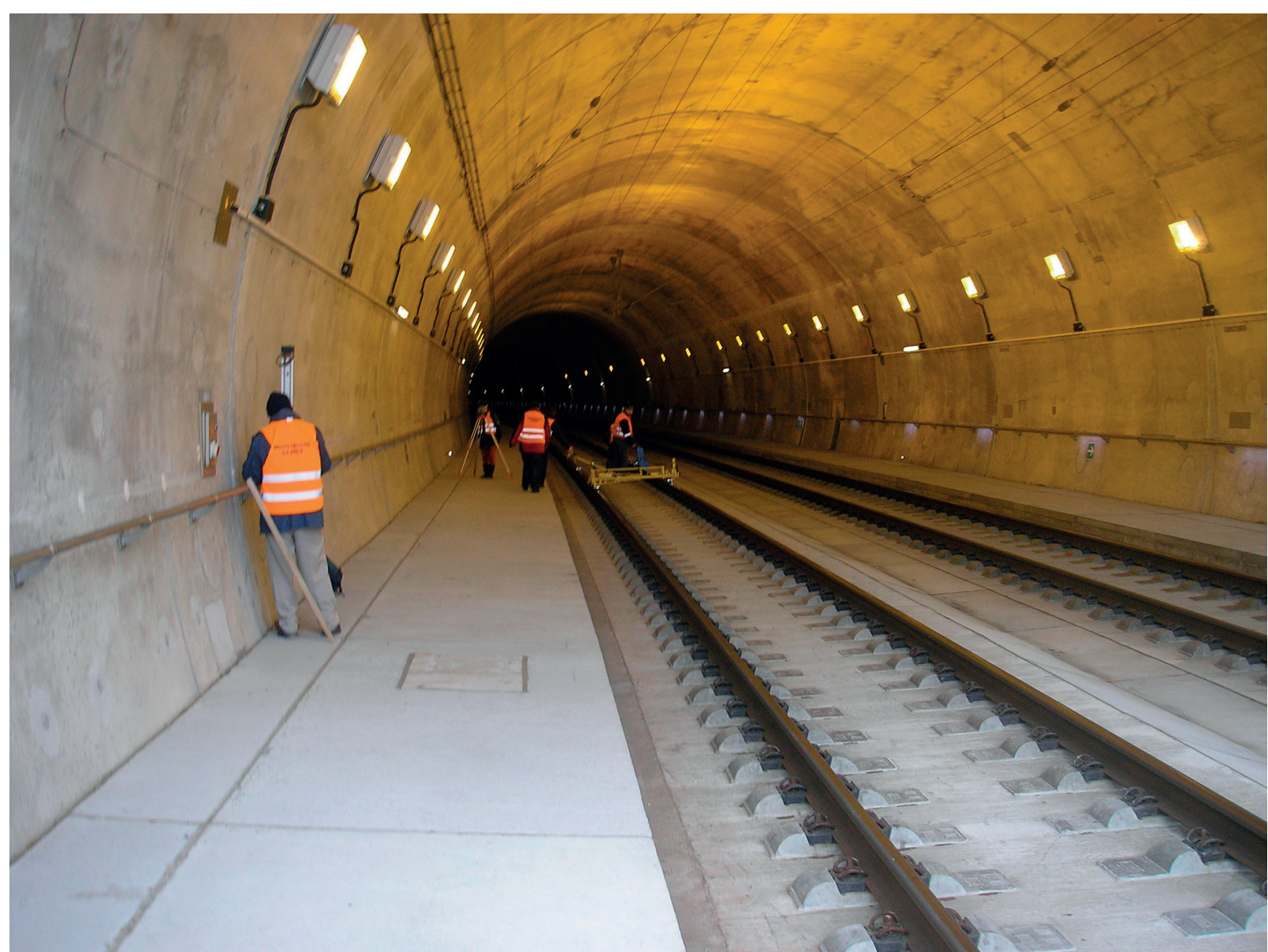

Fig. 1 View of the slab track structure in the tunnel Turecky vrch

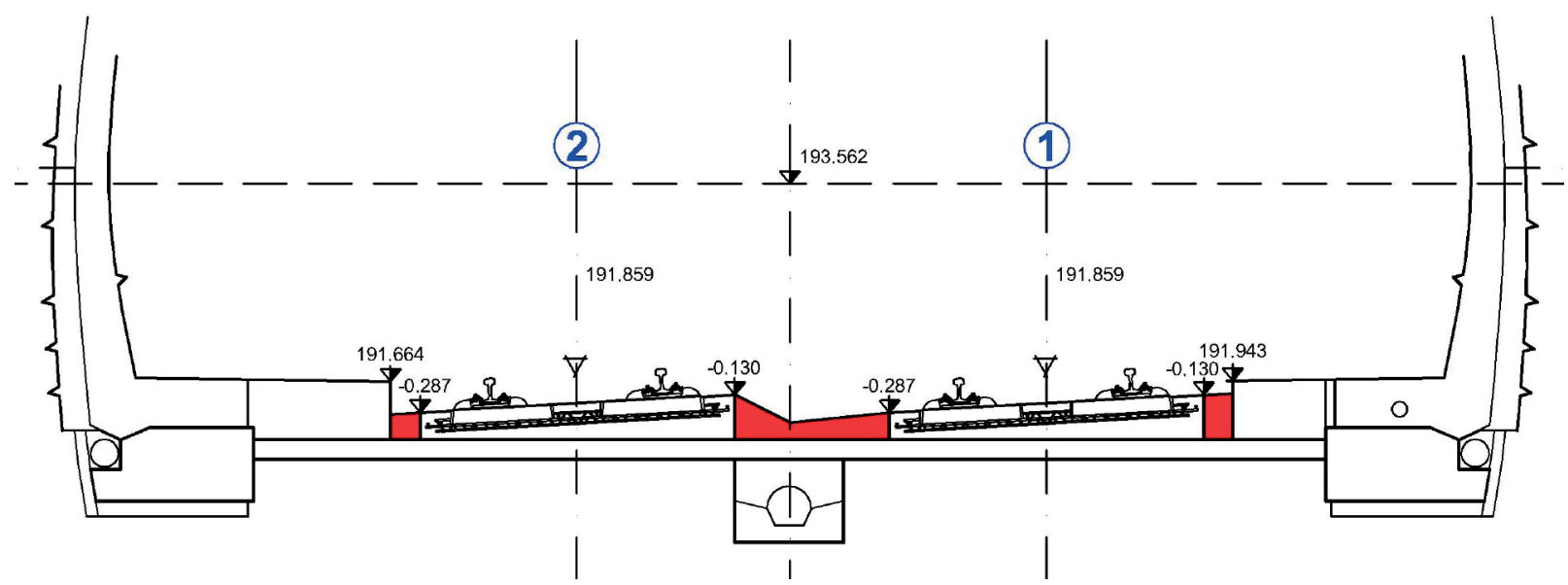

Fig. 2 The structural design of the slab track in the tunnel (concrete filling - marked in red) 


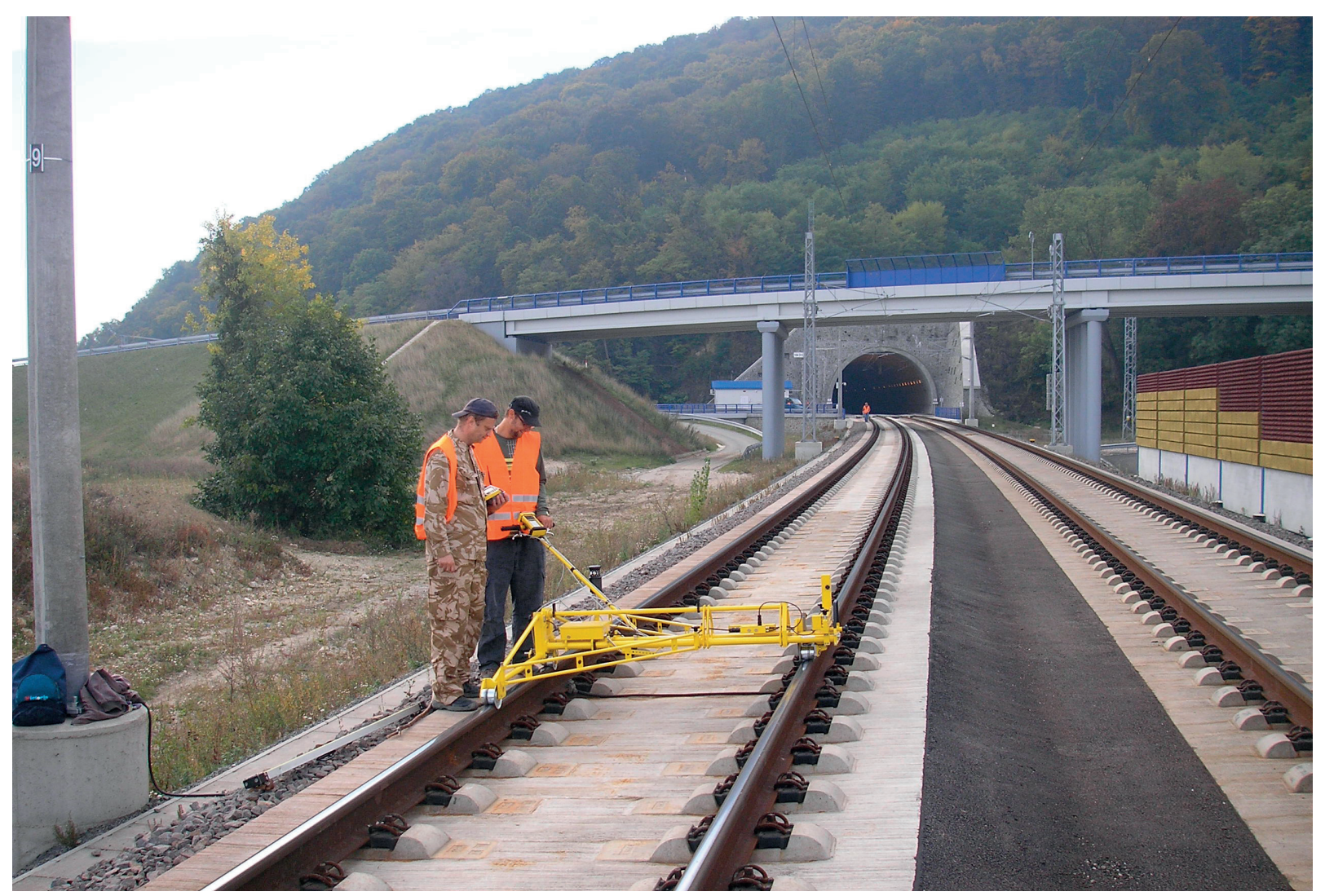

Fig. 3 View of the slab track structure in the area of earthwork (diagnostics of the alignment of track of the track using the KRAB ${ }^{T M}$ - Light device)

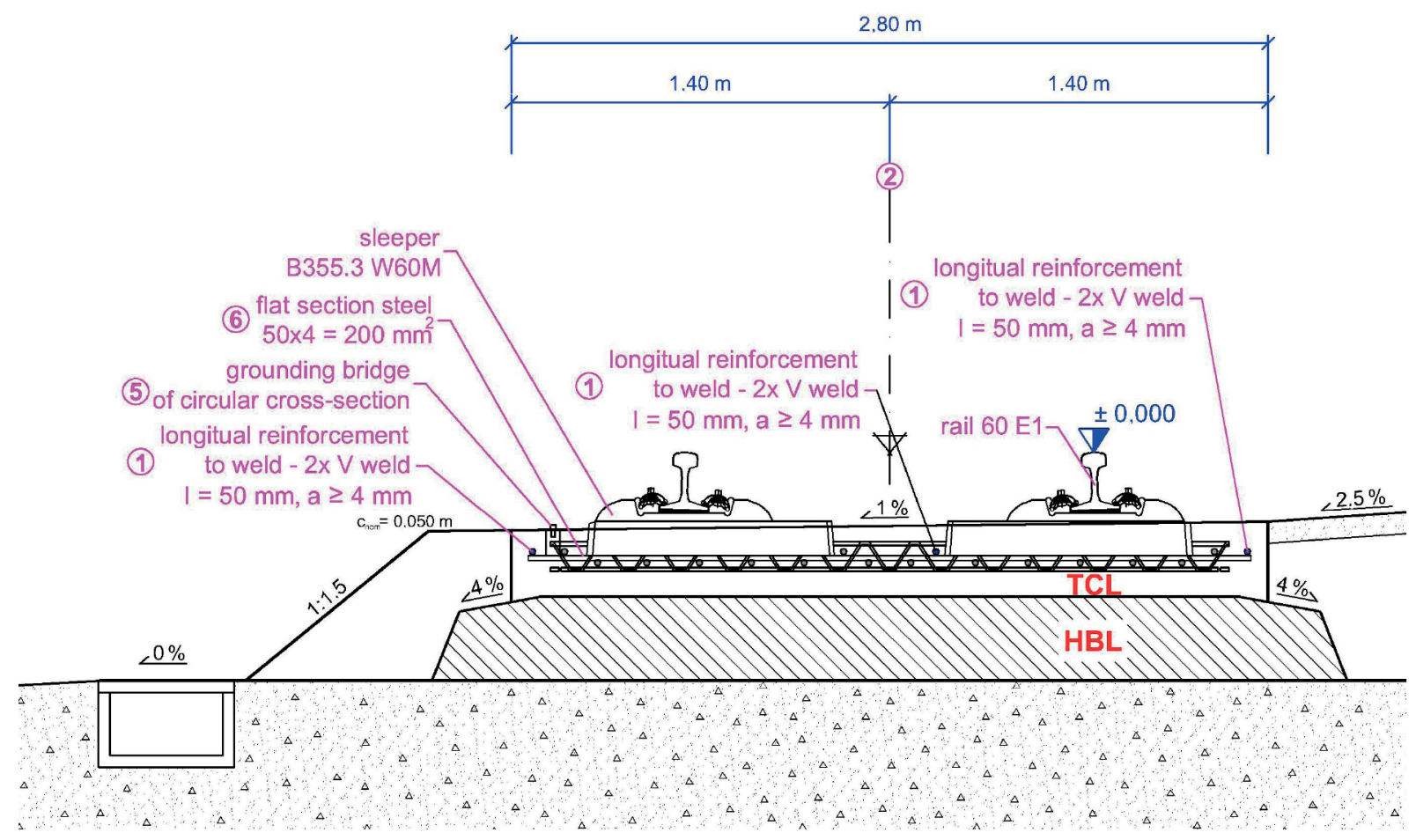

Fig. 4 Cross-section of the slab track structure placed on earthwork 


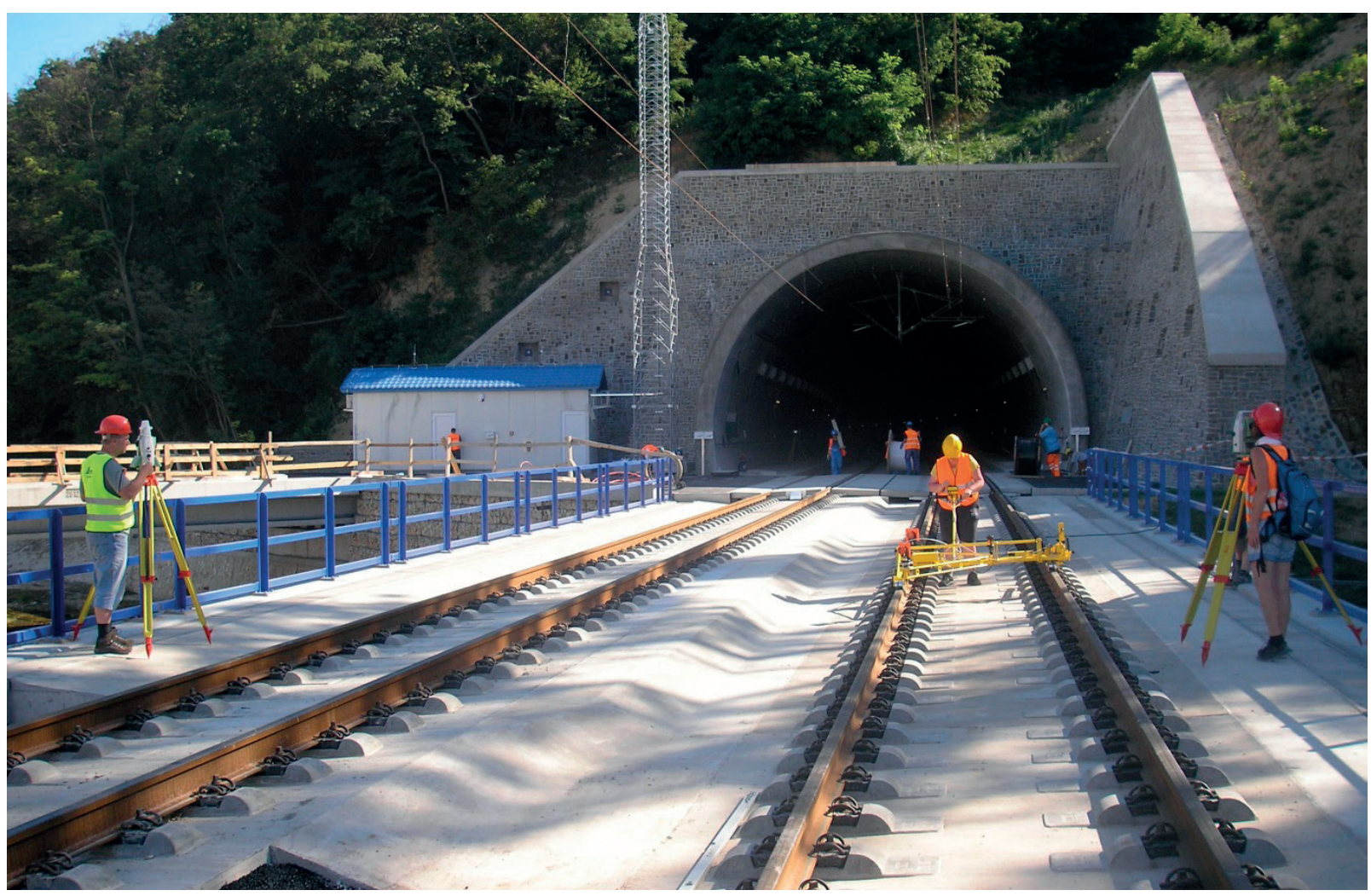

Fig. 5 View of the slab track structure of the railway bridge (diagnostics of actual and relative position of the track realized)

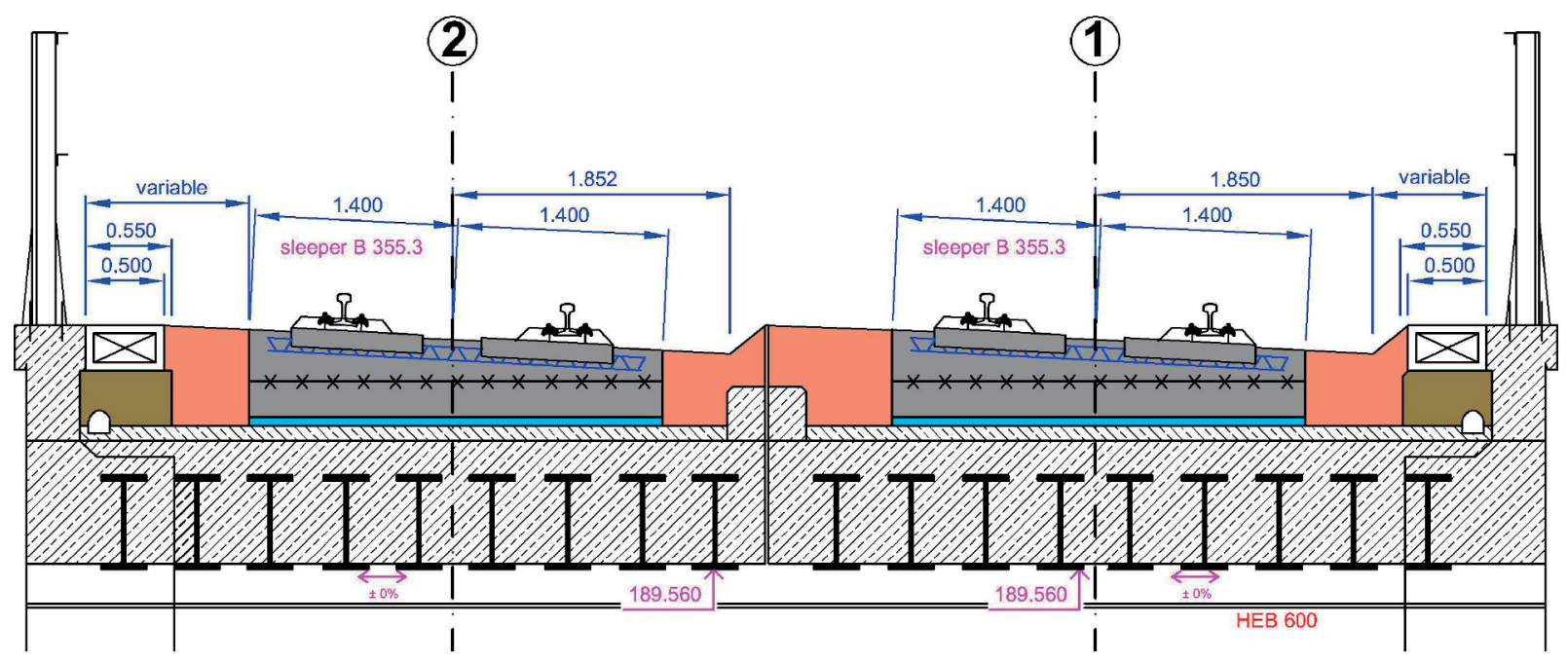

Fig. 6 Cross-section of the slab track structure placed on bridges

The critical point of the slab track structure is its completion and transition to the standard structure of railway superstructure - Figs. 7 and 8. In terms of dynamic effects, this is a place with the change of stiffness and, hence, this place was given special attention. The concrete bed of the length of $20 \mathrm{~m}$ was designed and implemented. It was lined with anti-vibration rubber mats of thickness $25 \mathrm{~mm}$ stuck on its bottom and sides and then filled with railway ballast material with track skeleton stored identical as in the adjacent track section with the standard structure of railway superstructure. 

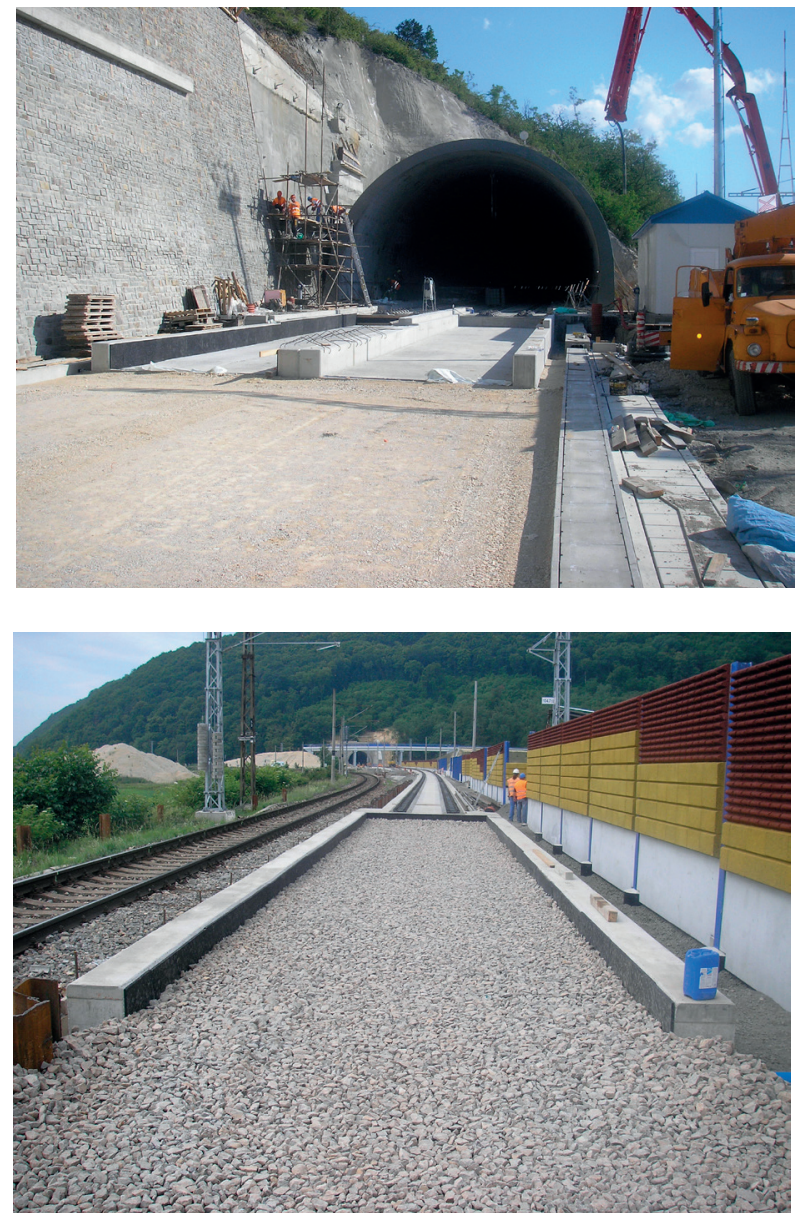

Fig. 7 View of the transition area built between the structure of the slab track and track section with standard structure of railway superstructure (left in the area of south portal and right in the area of north portal)

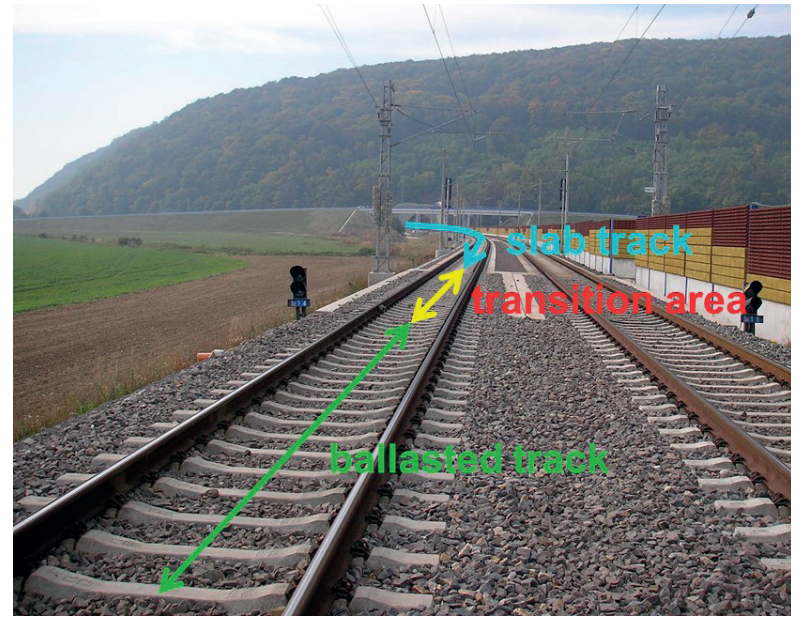

Fig. 8 View of the transition area built between the structure of the slab track and the standard structure of railway superstructure
With regard to the required quality characteristics and service life declared, the structure of the slab track is monitored at regular intervals in the area of both portals, transition sections and adjacent track sections with standard structure of railway superstructure for the purposes of DG ZSR within the scientific and research project from the time of delivering the modernized track section into operation. Input measurements were always made just before putting the tracks into operation (in period 10.07. - 11.07.2012 track No. 2 and 02.10. - 04.10.2012 track No. 1) and they resided, as any other measurements, in the implementation of a comprehensive continuous diagnostics of relative track geometry using manual measuring trolley $\mathrm{KRAB}^{\mathrm{TM}}$ - Light and also the diagnostics of gauge and elevation in each fastening node using a portable gauge-measurer ROBEL and geodetic positioning of geometric track position, its longitudinal profile as well as the position of the underneath surface of the sleeper - the slab track structures. After these input measurements, there are subsequently carried out operating measurements in the six-month period (every spring and autumn of that year). The monitoring is realized by the Department of Railway Engineering and Track Management in cooperation with the Department of Geodesy of the Faculty of Civil Engineering of the University of Zilina, and in cooperation with the manager of the railway infrastructure - Railways of the Slovak Republic and its Research and Development Institute of Railways (VVUZ) - Figs. 3 and 5. The monitoring on both portals of the tunnel Turecky vrch is focused on a comprehensive diagnostics of the relative and absolute geometric parameters of the track of the slab track in the tunnel (length of $100 \mathrm{~m}$ ) behind the portal, in the area of transition section of the structure and in the area with the standard structure of railway superstructure (length of $100 \mathrm{~m}$ ). The track section is monitored in south portal from new $\mathrm{km} 102.360$ to new $\mathrm{km} 102.535$ (length of $175 \mathrm{~m}$ ) and in the area of south portal from new $\mathrm{km} 104.200$ to new $\mathrm{km} 104.840$ (length of $640 \mathrm{~m}$ ) in total length of $815 \mathrm{~m}$. The monitoring is planned during the guarantee period for construction works (up to 2016) where it is expected that the relevance of the implementation of the slab track is shown in this track section modernized and, at the same time, the above mentioned advantages of the operation of the structural system of railway superstructure are confirmed in terms of the Railways of the Slovak Republic as well.

\section{Preliminary results of the monitoring of track geometry quality - a comprehensive diagnostics of the relative track geometry}

In this paper, only the diagnostics results of relative track geometry are presented also in relation to the previously realized diagnostics of structural layers built, which are part of the slab track subgrade, or subgrade structure and which was implemented in the inspection of the quality of the track section built between 
2011 and 2012. Diagnostics of relative track geometry of the track section built was implemented three times so far and immediately before putting line tracks into operation in 2012 and then in the spring and, of 2013 [4] and [5]:

1. In track No. 1, section No. 1 (new km 102.360000 - new km 102.535000 ) and section No. 2 (new km 104.200000 - new $\mathrm{km} 104.840$ 000) 03.10.2012 (measurement before putting sections into operation /MSO/), 09.04.2013 (first operational measurement $/ \mathrm{PO} 1 /$ ) and 08.10.2013 (second operational measurement $/ \mathrm{PO} 2 /$ ).

2. In track No. 2, section No. 1 and section No. 2 10.07.2012 (MSO), 22.04.2013 (PO1) and 22.10.2013 (PO2).
The sections diagnosed are part of the train section of the railway station Nove Mesto nad Vahom - Railway station. In 2012, the working load was of 7.4435 million tons which corresponds to $4^{\text {th }}$ category of track (source: ZSR).

Within the diagnostics of relative track geometry realized continuously using measuring device (measuring trolley $\mathrm{KRAB}^{\mathrm{TM}}$ - Light), the following parameters are detected on the base of primarily measured values [6]:

1. Track gauge RK $(\mathrm{mm})$.

2. Change of gauge ZR ( $\mathrm{mm} / \mathrm{m})$.

3. Track superelevation $\mathrm{PK}(\mathrm{mm})$.

4. Track twist, rated above the respective base $\mathrm{ZK}(\mathrm{mm} / \mathrm{m})$.

Quality of section 1 in track No. 1

Table 1

\begin{tabular}{|c|c|c|c|c|c|c|c|c|c|c|c|c|c|c|}
\hline \multirow{2}{*}{ 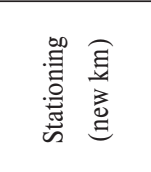 } & \multirow{2}{*}{ 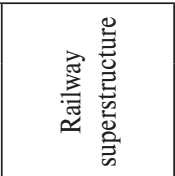 } & \multirow{2}{*}{ 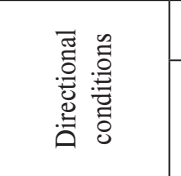 } & \multicolumn{4}{|c|}{ MSO (03.10.2012) } & \multicolumn{4}{|c|}{ PO1 (09.04.2013) } & \multicolumn{4}{|c|}{ PO2 (08.10.2013) } \\
\hline & & & 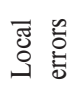 & $\stackrel{O}{\Sigma}$ & z & 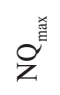 & $\begin{array}{l}\overline{\mathscr{J}} \\
\text { 品 }\end{array}$ & $\stackrel{O}{\Sigma}$ & Z & 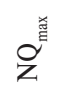 & 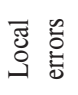 & $\stackrel{O}{\Sigma}$ & z & 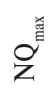 \\
\hline 102.360000 & \multirow{2}{*}{ SSRS } & & \multirow{2}{*}{9} & & & & \multirow{2}{*}{0} & & & & \multirow{2}{*}{0} & & & \\
\hline 102.460500 & & & & & & & & & & & & & & \\
\hline \multirow{2}{*}{102.480500} & Transition area & $\begin{array}{l}\text { Straight } \\
\text { section }\end{array}$ & 0 & 1.15 & 1.55 & & 0 & 1.66 & 2.12 & & 0 & 1.19 & 2.10 & \\
\hline & \multirow{3}{*}{ Slab track } & & \multirow{3}{*}{0} & & & 2.3 & \multirow{3}{*}{0} & & & 3.6 & \multirow{3}{*}{0} & & & 3.6 \\
\hline 102.487250 & & \multirow[b]{2}{*}{$\begin{array}{c}\text { Transition } \\
\text { curve and curve }\end{array}$} & & & & & & & & & & & & \\
\hline 102.535000 & & & & & & & & 2.87 & 1.59 & & & 2.19 & 1.18 & \\
\hline
\end{tabular}

Quality of section No. 2 in track No. 1

Table 2

\begin{tabular}{|c|c|c|c|c|c|c|c|c|c|c|c|c|c|c|}
\hline \multirow{2}{*}{ 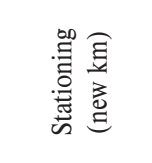 } & \multirow{2}{*}{ 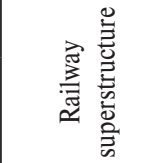 } & \multirow{2}{*}{ 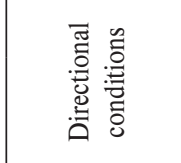 } & \multicolumn{4}{|c|}{ MSO (03.10.2012) } & \multicolumn{4}{|c|}{ PO1 (09.04.2013) } & \multicolumn{4}{|c|}{ PO2 (08.10.2013) } \\
\hline & & & త్ర్ & $\stackrel{O}{\Sigma}$ & $\stackrel{O}{z}$ & $\stackrel{\curvearrowright}{Z}^{\stackrel{.}{g}}$ & త్రુ & $\stackrel{O}{\Sigma}$ & Z & 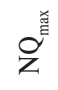 & 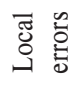 & $\stackrel{O}{\Sigma}$ & $\stackrel{O}{Z}$ & 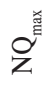 \\
\hline 104.200000 & \multirow{3}{*}{ Slab track } & Transition curve & \multirow{3}{*}{0} & \multirow{4}{*}{0.65} & \multirow{4}{*}{1.21} & \multirow{4}{*}{2.3} & \multirow{3}{*}{0} & 216 & 107 & \multirow{4}{*}{3.6} & \multirow{3}{*}{0} & \multirow{3}{*}{2.23} & \multirow{3}{*}{1.04} & \\
\hline 104.716000 & & & & & & & & & & & & & & \\
\hline \multirow{2}{*}{104.720000} & & & & & & & & & & & & & & 3.6 \\
\hline & Transition area & Straight section & 0 & & & & 0 & 0.75 & 1.24 & & 0 & 0.93 & 1.50 & \\
\hline & \multirow[t]{2}{*}{ SSRS } & & \multirow[t]{2}{*}{1} & & & & \multirow[t]{2}{*}{0} & & & & \multirow[t]{2}{*}{0} & & & \\
\hline 104.840000 & & & & & & & & & & & & & & \\
\hline
\end{tabular}


5. Longitudinal vertical position of left and right rail VL, VR ( $\mathrm{mm})$.

6. Directional position of left and right rail SL, SR (mm).

As already mentioned, first activities were made before putting line tracks No. 1 and No. 2 into operation in 2012 within diagnostics of above characterized track section. The effect of subsequent repair activities (rail grinding, track lining and levelling), implemented under maintenance operations of railway infrastructure manager between the measurements in 2012 and 2013, was not taken into account in the evaluation of relative track geometry, as the working site performing monitoring was not provided with these results of activities.

The development of track geometry (hereinafter referred to as RK) of the monitored sections of southern and northern portal of the tunnel Turecky vrch is shown in Table 1 to Table 4 . In the detection of maintenance limits, the quality of the straight section or section in transition curve and curve is specifically evaluated in accordance with [7]. Local errors of the parameters measured are calculated separately for sections with the standard structure of railway superstructure (SSRS), for transition areas and sections with the slab track structure.

The overall superevaluation of test sections (so called "section evaluation") is, in accordance with [1], given by the quality number of the section evaluated $(\mathrm{QN})$, and quality mark (QM) of SP parameters (SL), RK, PK and VR (VL).

The evaluation of section by the number of quality, calculated according to the equation:

$Q N=\sqrt{0,57 . S D V_{R K}^{2}+1,6 . S D V_{S P, S L}^{2}+1,6 . S D V_{P K}^{2}+1,6 . S D V_{V P, V L}^{2}}$

Quality of section No. 1 in track No. 2

Table 3

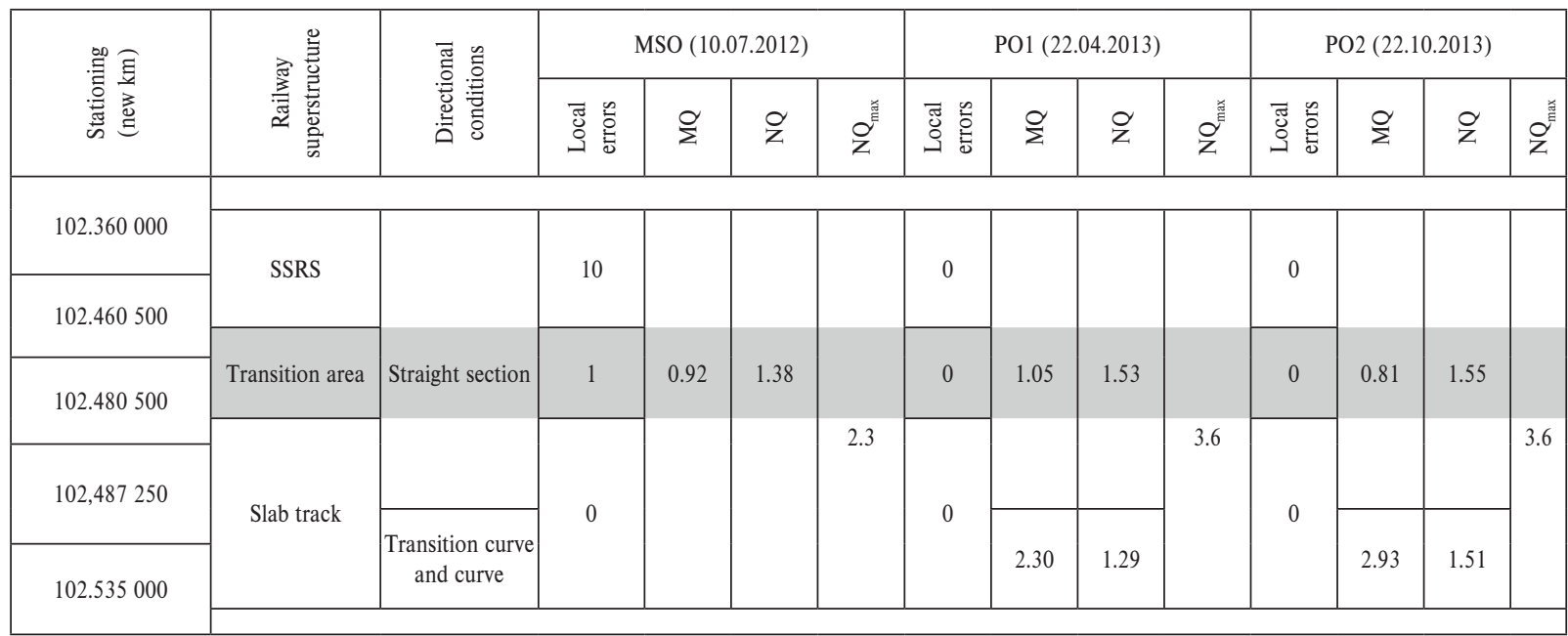

Quality of section No. 2 in track No. 2

Table 4

\begin{tabular}{|c|c|c|c|c|c|c|c|c|c|c|c|c|c|c|}
\hline \multirow{2}{*}{ 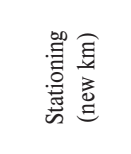 } & \multirow{2}{*}{ 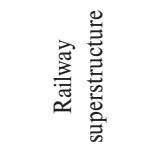 } & \multirow{2}{*}{ 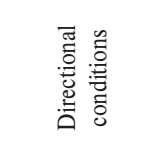 } & \multicolumn{4}{|c|}{ MSO (10.07.2012) } & \multicolumn{4}{|c|}{ PO1 (22.04.2013) } & \multicolumn{4}{|c|}{ PO2 (22.10.2013) } \\
\hline & & & 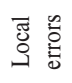 & $\stackrel{\sigma}{\Sigma}$ & $\stackrel{O}{z}$ & 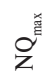 & 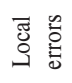 & $\stackrel{\alpha}{\Sigma}$ & Z & 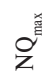 & 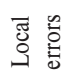 & $\stackrel{\circ}{\Sigma}$ & z & $\stackrel{\text { 盖 }}{2}$ \\
\hline 104.200000 & & & & & \multirow[b]{3}{*}{1.31} & \multirow[b]{3}{*}{2.3} & \multirow{3}{*}{0} & \multirow{3}{*}{2.35} & \multirow{3}{*}{1.19} & & \multirow{3}{*}{0} & \multirow{3}{*}{2.35} & \multirow{3}{*}{1.14} & \\
\hline 104.716000 & \multirow[t]{2}{*}{ Slab track } & $\begin{array}{c}\text { Transition curve } \\
\text { and curve }\end{array}$ & \multirow[t]{2}{*}{2} & \multirow[b]{2}{*}{0.71} & & & & & & & & & & \\
\hline \multirow{2}{*}{104.720000} & & & & & & & & & & 3.6 & & & & 3.6 \\
\hline & Transition area & $\begin{array}{l}\text { Straight } \\
\text { section }\end{array}$ & 0 & & & & 0 & 0.90 & 1.38 & & 0 & 0.70 & 1.46 & \\
\hline 104.840000 & SSRS & & 6 & & & & 0 & & & & 0 & & & \\
\hline
\end{tabular}


where:

$S D V_{R K} \quad$ - Standard deviation of variable of track gauge,

$S D V_{S P, S L}$ - Standard deviation of variable of direction of the track, $S D V_{P K} \quad$ - Standard deviation of variable of track superelevation,

$S D V_{V P, V L}$ - Standard deviation of variable of longitudinal track height.

where $S D V=\sqrt{\frac{1}{n-1} \sum_{i=1}^{n} x_{i}^{2}}(\mathrm{~mm})$

expresses irregular course of track geometry parameter in the section evaluated where:

$n$ - number of points measured after $0.25 \mathrm{~m}$,

$i$ - marking measuring point,

$x_{i}$ - dynamic component of the relevant quantity of track geometry (deviation from the center line in the wavelength range $1 \mathrm{~m}$ to $25 \mathrm{~m})$.

The evaluation of section according to quality marks shall be carried out according to the equation:

$Q M=\frac{\ln \frac{S D V}{b}}{m}$

where $b$ and $m$ are numerical constants determined on the basis of the SDV statistics of relevant parameter and speed zone.

The results of quality section evaluation of track according to quality marks are indicative and additional on the railway tracks of the Slovak Republic and are not binding for the evaluation of TG state. Measures, which are set for individual intervals of quality marks, can provide only recommendations:

a) where $0<\mathrm{QM} \leq 2$, state of track geometry is satisfactory in section evaluated,

b) where $2<\mathrm{QM} \leq 3$, it is recommended to design the repair of track geometry in the section evaluated into maintenance work plan,

c) where $3<\mathrm{QM}<4$, it is recommended to perform the repair of track geometry in the section evaluated to the nearest control,

d) where $4 \leq \mathrm{QM} \leq 6$, it is recommended to perform immediate measures in the section evaluated to ensure the safety of operation [1].

\section{Comparison of gauge and elevation measurements before putting test section into operation, the first operational measurement and the second operational measurement}

The difference of values of gauge deviations found in PO1 and MSO is in the range from $1.27 \mathrm{~mm}$ in track No. 2, section No. 1 to $-0.74 \mathrm{~mm}$ in track No. 1 , section No. 2. The difference of values of gauge deviations in $\mathrm{PO} 2$ and $\mathrm{MSO}$ is in the range from $1.67 \mathrm{~mm}$ in track No. 2, section No. 2 to $-2.57 \mathrm{~mm}$ in track No. 2, section No. 2. The difference of values of gauge deviations in PO2 and PO1 ranges (excluding the section No. 2 in track No. 2) at an average range of about $0.3 \mathrm{~mm}$. There are higher values in all three subsections of section No. 2 of track No. 2: in the section of the structure with the slab track, in the transition area and the section with the standard structure of railway superstructure. The values are in the range from $0.92 \mathrm{~mm}$ in track No. 2, section No. 2 to $-3.05 \mathrm{~mm}$ in track No. 2 , section No. 2 .

The difference of values of track elevation found in PO1 and MSO is in the range from $3.36 \mathrm{~mm}$ in track No. 1 , section No. 2 to $-5.27 \mathrm{~mm}$ in track No. 2, section No. 2. The difference of values of track elevation found in $\mathrm{PO} 2$ and $\mathrm{MSO}$ is in the range of $4.35 \mathrm{~mm}$ in track No. 2, section No. 2 to $-5.19 \mathrm{~mm}$ in track No. 1, section No. 1. The difference of values of track elevation measured in $\mathrm{PO} 2$ and $\mathrm{PO} 1$ ranges at an average range of about $1 \mathrm{~mm}$. Higher values of differences of track elevation occur in all three subsections of the sections: in the section of the structure of slab track, in the transition area as well as the section with the standard structure of railway superstructure. Values are in the range from $3.51 \mathrm{~mm}$ in track No. 2, section No. 2 to $-1.50 \mathrm{~mm}$ in track No. 1, section No. 1.

The ranges of differences of gauge deviation values $\Delta \mathrm{RK}$ and deviations of track elevation PK are shown in Table 5.

\section{Analysis of the possible causes of deviations in track geometric parameters of the track}

Static load tests (SLTs) were implemented at the level of subgrade and on the surface of individual structural layers of the track in the sections of the railway track built between 2011 and 2012. Continuous testing of the structural parts in question using SLT has achieved that there have been immediately obtained an overview of the quality of the incorporation of individual rock materials (determining the degree of compaction) and deformation resistance reached in the level of structural layer tested expressed by static module of deformation $E_{s, i}$.

Static load tests were carried out in (Fig. 9) [4] and [5]:

1. Subgrade.

2. Surface of frost-resistant protective layer (in the case of sections with slab track and their adjacent transition section) or sub-ballast layer (in the case of track sections with the standard structure of railway superstructure).

3. Surface layer of railway ballast in the structural thickness of pre-tipped ballast (about the level of loading area of sleepers) in the transition sections and track sections with the standard structure of railway superstructure.

On the basis of comprehensive diagnostics of the relative track geometry it is possible to identify some trends in the growth of deviations in places where the desired values of compaction degrees or deformation resistance were not reached, whose origin may resulted just in the deficiencies in the structure of railway substructure [7]. 
Differences of values $\triangle \mathrm{RK}$ and $\mathrm{PK}$ measured within MSO, PO1 and PO2

Table 5

\begin{tabular}{|c|c|c|c|c|c|c|c|c|c|c|c|c|}
\hline \multirow{2}{*}{ Track/section } & \multicolumn{4}{|c|}{$\Delta$ RK value $(\mathrm{mm})$} & \multicolumn{6}{c|}{ PK value (mm) } \\
\cline { 2 - 15 } & PO1 - MSO & \multicolumn{2}{|c|}{ PO2 - PO1 } & \multicolumn{1}{|c|}{ PO2 - MSO } & \multicolumn{2}{|c|}{ PO1 - MSO } & \multicolumn{2}{|c|}{ PO2 - PO1 } & \multicolumn{2}{c|}{ PO2 - MSO } \\
\cline { 2 - 14 } & max. & min. & max. & min. & max. & min. & max. & min. & max. & min. & max. & min. \\
\hline Track No. 1/ section 1 & 0.72 & -0.52 & 0.17 & -0.61 & 0.63 & -0.62 & 0.22 & -4.89 & 1.92 & -1.50 & 0.85 & -5.19 \\
\hline Track No. 1/ section 2 & 1.27 & -0.74 & 0.11 & -0.32 & 1.06 & -0.92 & 3.36 & -4.27 & 2.12 & -0.73 & 3.97 & -3.14 \\
\hline Track No. 2/ section 1 & 0.67 & -0.63 & 0.02 & -0.45 & 0.44 & -0.70 & 1.20 & -4.42 & 2.61 & -0.77 & 1.76 & -3.22 \\
\hline Track No. 2/ section 2 & 0.95 & -0.55 & 0.92 & -3.05 & 1.67 & -2.57 & 2.96 & -5.27 & 3.51 & -1.25 & 4.35 & -4.63 \\
\hline
\end{tabular}
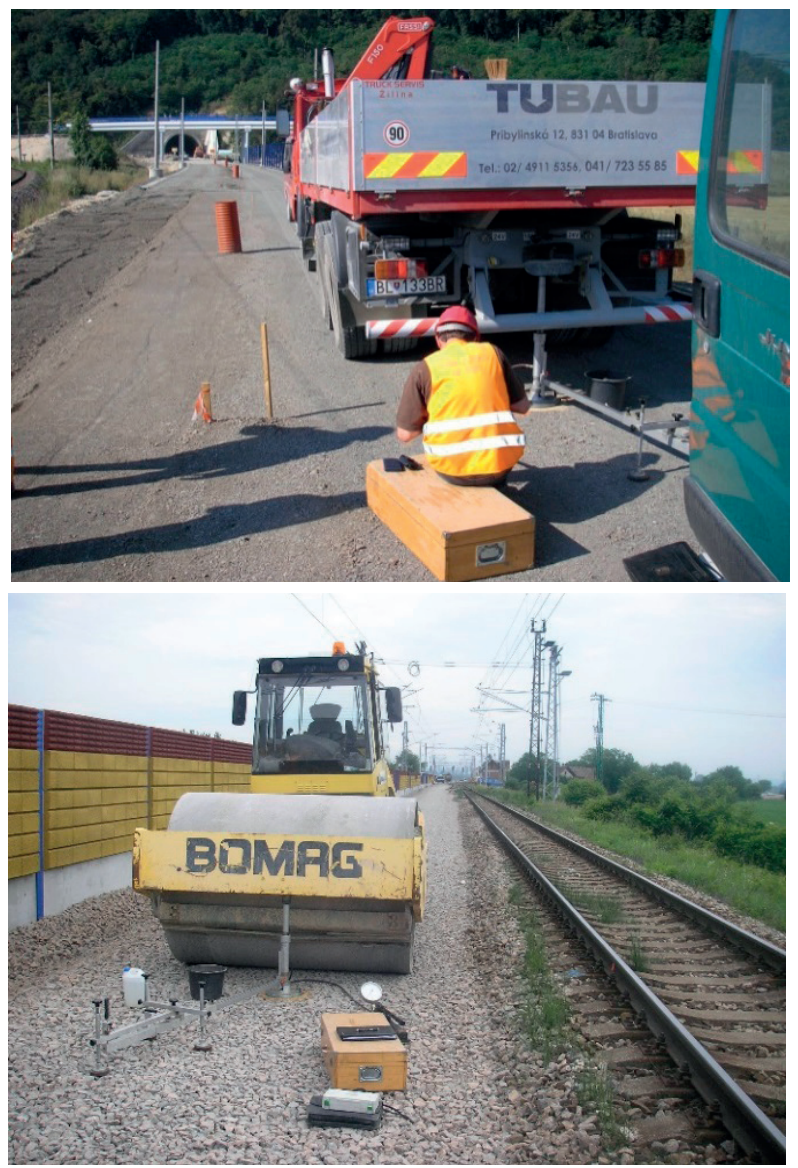

Fig. 9 Implementation of the static loading test in the northern portal (left on the surface of frost-resistant protective layer in the area of slab track, right on the surface of the railway ballast

in the area with standard structure of railway superstructure)

The places of origin of negative trends in the values of the track geometry on the basis of the deficiencies in the structure of railway subgrade are shown in Table 6. The places where the desired value of the deformation module was not achieved, or quality of consolidation are marked in red, the parameter values of track geometry which show a negative trend, and it is appropriate to monitor them closely are marked in blue).
It is clear from Table 6 that in some places in which the required value of the static module of changes $E_{s, i}$ or consolidation quality $E_{\text {def } 2} / E_{\text {def } 1}$ has not been reached, parameters of track geometry show a negative trend, therefore, it is possible to predict that the worsening trend of parameter deviations of track geometry may have originated in the deficiencies in the deformation resistance or consolidation of the structural layers of slab track, or subgrade structure when operating.

Directional and vertical routing of a railway line does not have a demonstrable impact on the negative tendencies in the deviations of the parameters of track geometry. The parameter values have also been monitored in other places that could be problematic (culverts, slab joints of the slab track structure, transition area wedges), but no clear errors in the track geometry apply to these places.

Complex diagnostics of relative track geometry shows similar deviations as in the sections with the standard structure of railway superstructure and the sections with the slab track structure as well. Significant deviations are not yet recorded in the transition areas between the conventional and unconventional structure of railway superstructure.

\section{Conclusions}

An essential precondition for the competitiveness of rail transport is the reliable operation of the railway lines, considering the technological understanding, it means a safer and more stable movement of vehicles along the track - rail. The development and validation of a number of technical solutions of slab track in the longer term can ensure the quality of the track geometry parameters, reduce maintenance costs, extend the service life of structure and increase the competitiveness and attractiveness of railway lines. The issue of modernization of the railway infrastructure, which is still very current, is an ideal opportunity to further application of progressive systems and elements of the structure of railway lines, among which the structure of slab track undoubtedly belongs to.

The results of continuous diagnostics of relative track geometry do not show local errors of parameters during operation in any of the diagnosed sections. The total numbers of quality 
Analysis of the causes of deviations in RK parameters

\begin{tabular}{|c|c|c|c|c|c|c|c|c|c|c|}
\hline 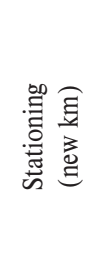 & 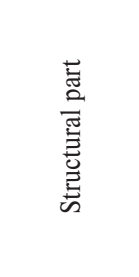 & 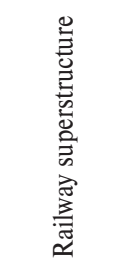 & 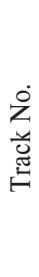 & 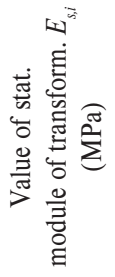 & 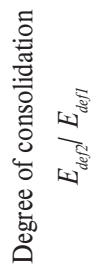 & 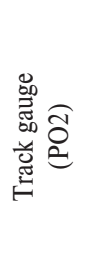 & 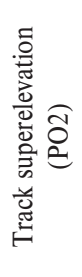 & 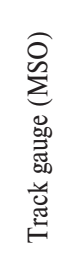 & 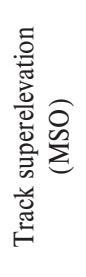 & 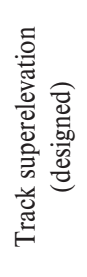 \\
\hline \multicolumn{11}{|c|}{ Area of southern portal } \\
\hline 102.365 & Subgrade & SSRS & 2 & 225.0 & 4.33 & 1.84 & -1.43 & 1.95 & -0.71 & 0 \\
\hline \multirow{3}{*}{102.375} & Subgrade & SSRS & \multirow{3}{*}{1} & 250.0 & 3.50 & \multirow{3}{*}{1.07} & \multirow{3}{*}{-1.82} & \multirow{3}{*}{1.09} & \multirow{3}{*}{0.94} & \multirow{3}{*}{0} \\
\hline & Earthworks & SSRS & & 75.0 & 3.60 & & & & & \\
\hline & $\begin{array}{c}\text { Railway } \\
\text { ballast }\end{array}$ & SSRS & & 93.8 & 3.30 & & & & & \\
\hline 102.425 & Subgrade & SSRS & 1 & 173.1 & 3.00 & 1.70 & -2.01 & 1.31 & 0.49 & 0 \\
\hline 102.465 & $\begin{array}{c}\text { Railway } \\
\text { ballast }\end{array}$ & $\begin{array}{c}\text { Transition } \\
\text { area }\end{array}$ & 1 & 22.0 & 1.67 & 1.10 & -2.24 & 0.81 & 0.86 & 0 \\
\hline \multicolumn{11}{|c|}{ Area of northern portal } \\
\hline 104.325 & Subgrade & Slab track & 1 & 140.6 & 2.86 & -0.20 & 85.15 & -0.12 & 83.49 & 84 \\
\hline 104.335 & Subgrade & Slab track & 2 & 132.4 & 3.29 & 1.77 & 84.67 & 1.53 & 83.69 & 84 \\
\hline 104.560 & Earthworks & Slab track & 2 & 132.4 & 3.43 & 0.54 & 83.76 & -0.37 & 82.44 & 84 \\
\hline 104.585 & Earthworks & $\begin{array}{l}\text { Bridge } \\
\text { wedge }\end{array}$ & 2 & 102.3 & 2.50 & 0.60 & 84.63 & -0.03 & 81.19 & 82.91 \\
\hline 104.600 & Earthworks & $\begin{array}{l}\text { Bridge } \\
\text { wedge }\end{array}$ & 1 & 375.0 & 2.33 & 0.13 & 72.95 & 0.32 & 73.57 & 72.31 \\
\hline 104.645 & Subgrade & Slab track & 2 & 75.0 & 2.53 & 1.07 & 46.17 & 0.71 & 43.91 & 45.43 \\
\hline 104.675 & Earthworks & Slab track & 1 & 125.0 & 2.63 & -0.54 & 27.27 & -0.20 & 25.83 & 25.56 \\
\hline 104.710 & Earthworks & Slab track & 2 & 93.8 & 2.20 & 0.91 & 6.36 & 0.76 & 3.58 & 0 \\
\hline 104.735 & $\begin{array}{c}\text { Railway } \\
\text { ballast }\end{array}$ & $\begin{array}{c}\text { Transition } \\
\text { area }\end{array}$ & 2 & 12.7 & 1.54 & 1.00 & -2.48 & 0.65 & -1.06 & 0 \\
\hline 104.810 & $\begin{array}{c}\text { Railway } \\
\text { ballast }\end{array}$ & SSRS & 1 & 72.6 & 2.79 & 0.05 & 1.64 & 0.08 & 1.15 & 0 \\
\hline
\end{tabular}

(QN) in diagnosed sections have even slightly improved within the second operating measurement in the four of the eight subsections as opposed to the first operating measurement (maximum improvement is from 1.59 to 1.18 ) and they slightly deteriorated in the other four partial sections (max. from 1.24 to $1.50)$.

On the basis of experimental measurements made so far, it is possible to expect that further development of the monitoring of RK in experimental section of the modernized track in the 


\section{COMMNICOIIONS}

area of tunnel Turecky vrch confirms the relevance of the application of slab track to the tracks which are standard, not only on the tracks for higher or high speeds. The application on these tracks represents the real benefit and basic precondition for the long-term safe, reliable, and in terms of maintenance cost, economically advantageous track structure.

\section{Acknowledgements}

There are partial results of the grant VEGA 1/0597/14 "Analysis of methods used to measure the unconventional railway track construction from the point of view of accuracy and reliability" in the paper.

\section{References}

[1] ZSR SR 103-8 (S) General Requirements for the Design, Construction, Repair, Maintenance and Acceptance of Construction Repair and Maintenance Works on the Slab Track Construction (in Slovak), GR ZSR, 2012

[2] IZVOLT, L., SESTAKOVA, J., VILIMEK, P.: The First Construction of Unconventional Type of Railway Superstructure in the ZSR Infrastructure. Proc. of $6^{\text {th }}$ intern. conference Concrete and Concrete Structures, Terchova: Vratna dolina, October 2013, 166-175, Procedia Engineering 65 (2013), Elsevier, 1877 - 7058

[3] IZVOLT, L., IZVOLTOVA, J., SESTAKOVA, J.: Influence of Construction of Railway Super-structure on Railway Quality. Proc. of the $6^{\text {th }}$ intern. scientific conference on Dynamics of Civil Engineering and Transport Structures and Wind Engineering - DYNWIND '2014, May 2014, Donovaly, ISBN 978-80-554-0844-6, p. 63-74

[4] IZVOLT, L. et al.: Monitoring of Sections of Non-conventional Constructions of the Railway Superstructure and the Transition Areas - $3^{\text {rd }}$ Stage. ZSR Modernization of Railway Track Nove Mesto nad Vahom - Puchov, km 100.500 to 159.100, part 24-32-01 Nove Mesto Trencianske Bohuslavice (in Slovak), Zilina : KZSTH : SvF: University of Zilina, 06/2013

[5] IZVOLT, L. et al.: Monitoring of Sections of Non-conventional Constructions of the Railway Superstructure and the Transition Areas - $4^{\text {th }}$ Stage. ZSR Modernization of Railway Track Nove Mesto nad Vahom - Puchov, km 100.500 to 159.100, part 24-32-01 Nove Mesto Trencianske Bohuslavice (in Slovak), Zilina : KZSTH : SvF : University of Zilina, 03/2014

[6] ZSR SR 103-7 (S) Measurement and Evaluation of Track Geometry by Measuring Trolley KRAB (in Slovak), GR ZSR, 2008.

[7] IZVOLTOVA, J., PISCA, P., KOTKA, V., MANCOVIC, M.: 3D Laser Scanning of Railway Line, Communications - Scientific Letters of the University of Zilina, vol. 15, No. 4, 2013, 80-84, ISSN 1335-4205. 